\title{
Structural characterization and subcellular localization of Drosophila organic solute carrier partner 1
}

Nguyen Tho Huu ${ }^{1,2}$, Hideki Yoshida ${ }^{1,2}$, Takanari Umegawachi ${ }^{1,2}$, Seiji Miyata ${ }^{1}$ and Masamitsu Yamaguchi ${ }^{1,2^{*}}$

\begin{abstract}
Background: Organic solute carrier partner 1 (OSCP1) is known to facilitate the transport of various organic solutes into cells and reported to play a role in cell growth and cell differentiation. Moreover, OSCP1 is known as a tumor suppressor gene that is frequently down-expressed in nasopharyngeal carcinomas and acute myeloid leukemia. However, the underlying mechanisms of action remain unclear and the subcellular localization of OSCP1 has yet to be determined in detail.
\end{abstract}

Results: Drosophila contains a single orthologue of OSCP1 (dOSCP1) that shares 58\% homology with its human counterpart. To study the expression pattern and subcellular localization of dOSCP1, we prepared a specific antibody. Subcellular localization analyses of dOSCP1 with these revealed localization in the plasma membrane, endoplasmic reticulum, Golgi apparatus and mitochondria, but no detection in cytosol. dOSCP1 signals were also detected in the nucleus, although at weaker intensity than in plasma membranes and subcellular organelles. In addition, native polyacrylamide gel electrophoresis analysis with and without $\beta$-mercaptoethanol treatment revealed that recombinant dOSCP1 forms dimers and trimers in solution. The dimer form of dOSCP1 could also be detected by Western immunoblot analyses in third instar larval extracts.

Conclusions: The data revealed that dOSCP1 localizes not only in the plasma membrane but also in the nucleus, ER, Golgi apparatus and mitochondria. It is therefore conceivable that this protein may interact with various partners or form multimeric complexes with other proteins to play multiple roles in cells, providing clues to understanding the functions of dOSCP1 during Drosophila development.

Keywords: Organic solute carrier partner 1, Drosophila, Subcellular organelle

\section{Background}

Transporter proteins play important roles in absorption and elimination of numerous endogenous molecules, as well as exogenous substances and their metabolites, from cells. Moreover, identification and characterization of transporter proteins are important for drug discovery and development [1]. The mechanisms involved in cellular transport of organic anions and cations have been studied and reviewed elsewhere [2-4]. Transporter proteins belong to two major superfamilies: solute carrier (SLC) and ATPbinding cassette $(\mathrm{ABC})[5]$. The SLC transporters include

\footnotetext{
* Correspondence: myamaguc@kit.ac.jp

'Department of Applied Biology, Matsugasaki, Sakyo-ku, Kyoto 606-8585, Japan

${ }^{2}$ Insect Biomedical Research Center, Kyoto Institute of Technology, Matsugasaki, Sakyo-ku, Kyoto 606-8585, Japan
}

two families consisting of the organic anion transporting polypeptides (OATPs) and the SLC22A group, which contains the organic cation transporters (OCTs) and the organic anion transporters (OATs) [6]. In general, transporters are designed to recognize a single substance or a group of very similar substances, although some carrier proteins such as OATPs show broad substrate specificities [6,7].

Recently, organic solute carrier protein 1 (OSCP1) was identified in mammals as a polyspecific solute carrier protein [8-11] and likely novel member of the SLC transporters. When expressed in Xenopus laevis oocytes, OSCP1 mediated high affinity transport of $\mathrm{p}$-aminohippurate $(\mathrm{PAH})$, tetraethylammonium, and a wide range of structurally diverse organic compounds including prostagladin E2, prostaglandin F2 $\alpha$, estron sulfate, glutarate, 
L-leucine, L-ascorbic acid and tetracycline [8-11]. These results suggest that OSCP1 mediates transport of various organic solutes into cells.

On the other hand the OSCP1 gene, also named as Oxidored-nitro domain-containing protein 1 (NOR1), has been identified as a tumor suppressor gene that is frequently down-expressed in nasopharyngeal carcinomas (NPCs) [12-16]. Moreover, the OSCP1 (NOR1) promoter region has been found to be frequently methylated in acute myeloid leukemia (AML) patients [17]. These data indicate that OSCP1 may play a role in genesis of NPC and AML, although the underlying mechanisms are not fully understood.

Most SLC22A super family proteins are predicted to consist of 12 transmembrane domains, with intracellular amino and carboxy-termini $[18,19]$, although organic solute transporter alpha (OST $\alpha)$ and beta (OST $\beta)$ contain 7 and 1 transmembrane domains, respectively [20]. However, the structure of OSCP1 has not yet been biochemically and physically characterized. In the present study, we therefore examined the structure of Drosophila melanogaster OSCP1 (dOSCP1). Native polyacrylamide gel electrophoresis analysis with and without $\beta$-mercaptoethanol treatment revealed that the recombinant $\mathrm{dOSCP} 1$ forms dimers and trimers in solution. The dimer form of dOSCP1 was further confirmed by Western immunoblot analyses with third instar larval extracts.

Subcellular localization of OSCP1 is controversial. Although it has been reported to localize in plasma membranes of human trophoblast cells and mouse Sertoli cells $[9,11]$, cytoplasmic localization has also been reported in mouse cerebral neuronal cells $[8,21]$ and human HeLa cells [14]. Therefore, in this study, we examined subcellular localization of dOSCP1 and revealed its presence in the plasma membrane, endoplasmic reticulum, Golgi apparatus, mitochondria and nucleus of cells. The data indicate that dOSCP1 plays not only in the transport of organic solutes through the cell membrane, but also into the organelles and nucleus, and consequently it may be involved in regulation of apoptosis, differentiation and/or proliferation.

\section{Results}

OSCP1 is an evolutionary conserved protein across species We used the NCBI database (http://www.ncbi.nlm.nih. gov/) to access information on OSCP1. The data showed that the OSCP1 gene is conserved among multiple species such as H.sapiens, P.troglodytes, M.mulatta, M.musculus, C.lupus, B.taurus, G.gallus, R.norvegicus, D.rerio, C. elegans and D.melanogaster, but not in S.cerevisiae. To gain insight into the relationships of the OSCP1 among individual species, sequence alignments were analyzed by ClustalW2 software. Identical amino acid residues are shaded in black and similar amino acid residues are in gray in Figure 1, and the highly conserved regions 1 and 2 are underlined. The similarity and identity of amino acid sequences of human OSCP1 (hOSCP1) and Drosophila (dOSCP1, CG13178) were found to be $58 \%$ and $30 \%$, respectively. The most highly conserved region 1 of hOSCP1 and dOSCP1 (aa63 to aa87) showed 92\% similarity and $48 \%$ identity. The highly conserved region 2 of these two proteins (aa103 to aa108) showed 100\% similarity and 57\% identity. These two conserved regions may thus play important roles in OSCP1 function, although further analyses are necessary to clarify this point.

\section{Expression and purification of recombinant dOSCP1 protein} The expression plasmid pCold-dOSCP1 and empty vector pColdI were transformed into the E. coli BL21 strain. Expression of the recombinant His-dOSCP1 fusion protein was induced by adding $0.5 \mathrm{mM}$ IPTG at $18^{\circ} \mathrm{C}$ for 15 hours. Most recombinant protein was found in the soluble fraction (data not shown) and Ni-NTA method was used to purify the His-dOSCP1 fusion protein for analysis by sodium dodecyl sulfate-polyacrylamide gel electrophoresis (SDS-PAGE). This latter detected a single $35 \mathrm{kDa}$ band on Coomassie Brilliant Blue G-250 (CBB) staining (Figure 2A). The dOSCP1 protein contains 302 amino acids and the calculated molecular weight is 34,607 , that is nearly identical in size to the detected band. The purity of the recombinant dOSCP1 in the final fraction was estimated to be more than $95 \%$. Western immunoblot analysis with monoclonal anti-His antibody showed the $35 \mathrm{kDa}$ band to truly represent the HisdOSCP1 (data not shown).

\section{Structural analysis of dOSCP1 by native PAGE}

To evaluate the possible multimer formation of dOSCP1, we performed native-PAGE analysis of recombinant dOSCP1 protein, treated with or without $4 \%$ SDS and $10 \% \beta$-mercaptoethanol with or without heating. The apparent dimer form of dOSCP1 was detected at the position corresponding to $70 \mathrm{kDa}$ when compared with the standard maker (Figure 2B, lanes 1 and 2). In addition a more slowly migrating band corresponding to $100 \mathrm{kDa}$ was also detected that could represent a trimer form of dOSCP1 under the native PAGE conditions. In any event, by this method, we first established that dOSCP1 can form multimers in solution.

Western immunoblot analysis with Canton S third instar larval extracts using anti-dOSCP1 antibody revealed a $35 \mathrm{kDa}$ dOSCP1 band (Figure 3A). The intensity of this was decreased by $40 \%$ in extracts of eye discs in which dOSCP1 double stranded RNA (dsRNA) was specifically expressed with GMR-GAL4 and UAS-dOSCP1IR (Figure 3B-C). The results thus indicated that the $35 \mathrm{kDa}$ band truly represents the dOSCP1 protein. The faint $70 \mathrm{kDa}$ band for the putative dimer form of dOSCP1 was also detected even under denaturing conditions with $4 \%$ 


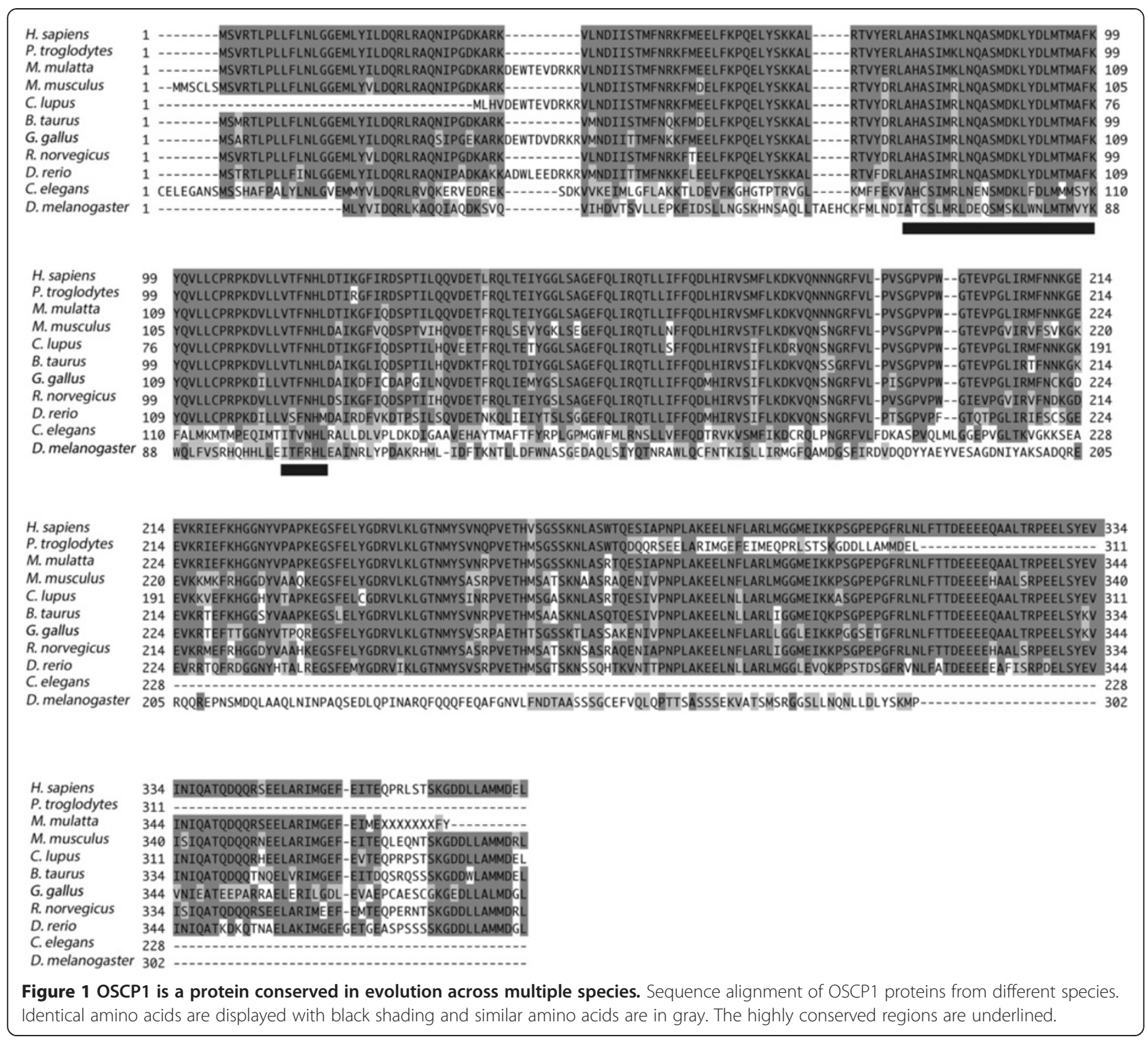

SDS and 10\% $\beta$-mercaptoethanol (Figure 3A), suggesting that dOSCP1 forms dimers in vivo. Dimer or multimer formation in the presence of SDS has been reported for Drosophila $\beta$-sarcoglycan [22] and mammalian sarcoglycans [23]. It has also been reported that some cell surface antigens such as HLA-DR, -DC1 and -B7 form dimeric or multimeric forms even with SDS-PAGE $[24,25]$.

\section{Subcellular localization of dOSCP1 protein in various Drosophila larval tissues}

The goal of our study was molecular, structural, and functional characterization of dOSCP1 protein localized in cells. As a first step towards this goal, the antidOSCP1 antibody was used to examine the expression pattern of the dOSCP1 protein in various tissues in the third instar larvae of Drosophila. Immunostaining results showed dOSCP1 to be expressed ubiquitously in various tissues including brain lobes, leg discs, wing discs, eye discs, fat bodies (Figure 4) and salivary glands (Figure 5). No signals were detected with the primary dOSCP1 antibody preincubated with the purified His-dOSCP1 fusion protein (Additional file 1: Figure S1), indicating specificity for the OSCP1 protein. Immunohistochemical results showed that dOSCP1 signals were mainly detectable in the cytoplasm as dotted or mesh-like structures (Figure 4A'-E"). Salivary glands showed strong dOSCP1 signals in the cell membrane and in a cytoplasmic mesh-like structure (Figure 5A-H). In the proximal regions of the glands, significant signals of dOSCP1 were also detected in the nucleus (Figure 5A-D). In contrast, no nuclear signals were detectable in the distal region (Figure 5E-H). 


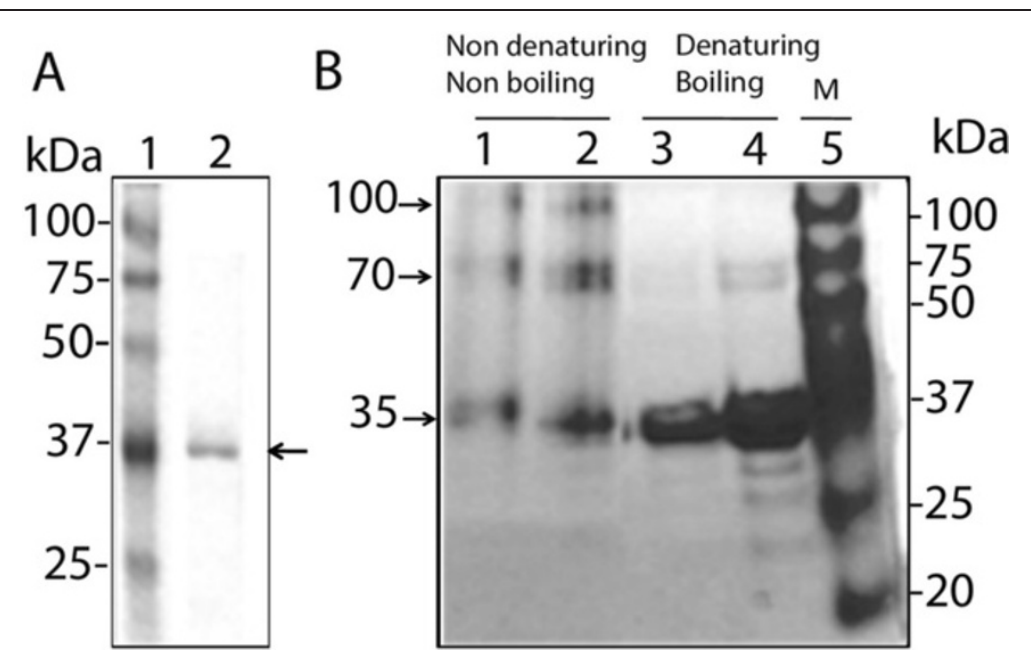

Figure 2 dOSCP1 forms dimers and trimers in solution. (A) Purified recombinant His-dOSCP1 protein was separated on SDS-PAGE containing 10\% acrylamide. The gel was then stained with Coomassie Brilliant Blue G-250. Lane 1: Precision protein standards (Bio-Rad) with molecular weights given in kilodaltons. Lane 2: purified His-dOSCP1 protein. The arrow indicates the $35 \mathrm{kDa}$ band. (B). Native PAGE analysis of the recombinant dOSCP1. Lanes 1 and 2: $2 \mu \mathrm{g}$ or $4 \mu \mathrm{g}$ of protein were treated with sample buffer containing no SDS, no $\beta$-mercaptoethanol and without boiling. The samples were separated on Native-PAGE containing 10\% acrylamide. The gel was then stained with Coomassie Brilliant Blue G-250. The bands detected were at $35 \mathrm{kDa}, 70 \mathrm{kDa}$ and $100 \mathrm{kDa}$ band. The $35 \mathrm{kDa}$ band corresponds to His-dOSCP1 recombinant protein, the $70 \mathrm{kDa}$ band likely represents the dimeric form and the $100 \mathrm{kDa}$ band may represent a trimeric form. Lanes 3 and $4: 2 \mu \mathrm{g}$ or $4 \mu \mathrm{g}$ of protein were treated with SDS sample buffer containing $4 \%$ SDS and 10\% $\beta$-mercaptoethanol in boiling water. Lane 3: the $70 \mathrm{kDa}$ band is not detectable. Land 4: A faint $70 \mathrm{kDa}$ band is evident. Lane 5: Precision protein standards (Bio-Rad) with molecular weights given in kilodaltons ( $\mathrm{kDa})$.

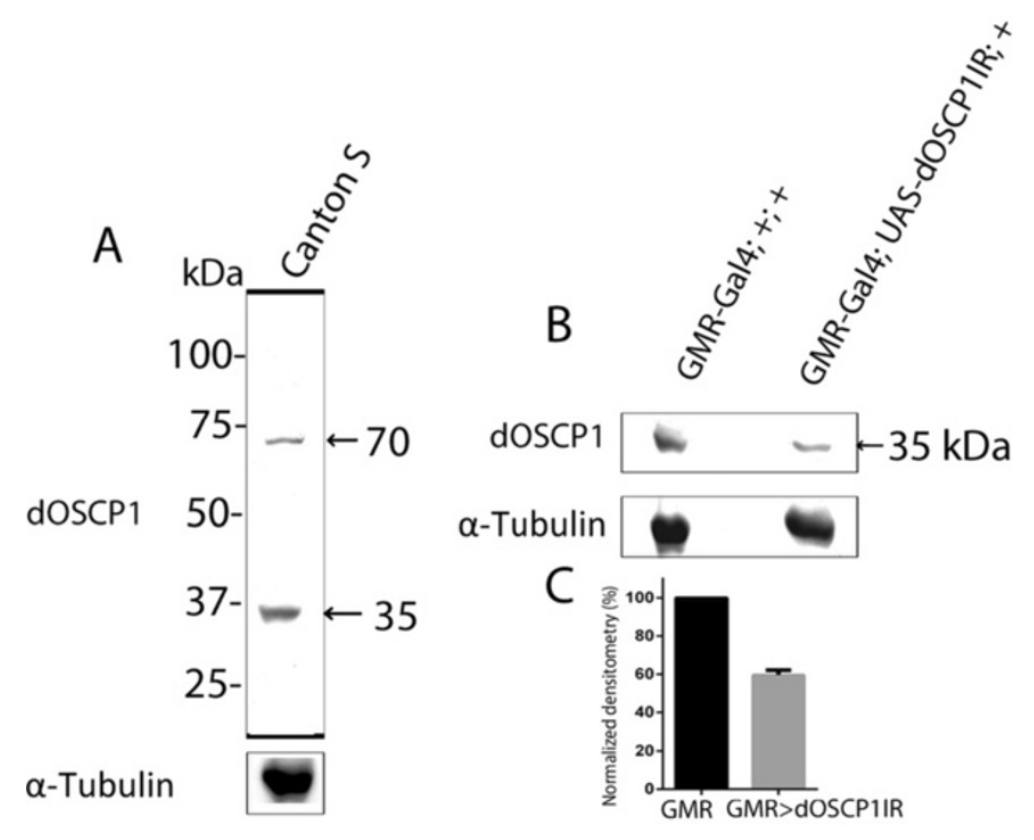

Figure 3 Western immunoblot analysis. (A) Proteins extracted from Canton S third instar larval whole bodies. The blots were probed with a Guinea pig polyclonal anti-OSCP1 antibody. In the immunoblotting, both $35 \mathrm{kDa}$ and $70 \mathrm{kDa}$ bands were detected. The $35 \mathrm{kDa}$ band corresponds to dOSCP1 protein. The faint $70 \mathrm{kDa}$ band likely represents the dimeric form. (B) Protein extracts of eye imaginal discs from GMR-Gal4; +; + (control flies) and GMR-Gal4; UAS-dOSCP1IR; + (knockdown flies). Knockdown of dOSCP1 led to decrease in the 35 kDa band when compared with control flies. (C) Quantification of the $35 \mathrm{kDa}$ band using Image Saver 6 software. The relative expression level was significantly decreased in knockdown flies ( ${ }^{*} \mathrm{P}<0.001$; Student $\mathrm{t}$ test; $\mathrm{n}=3 ; 30 \mathrm{\mu g}$ of proteins per replicate). a-Tubulin was used as a loading control. 


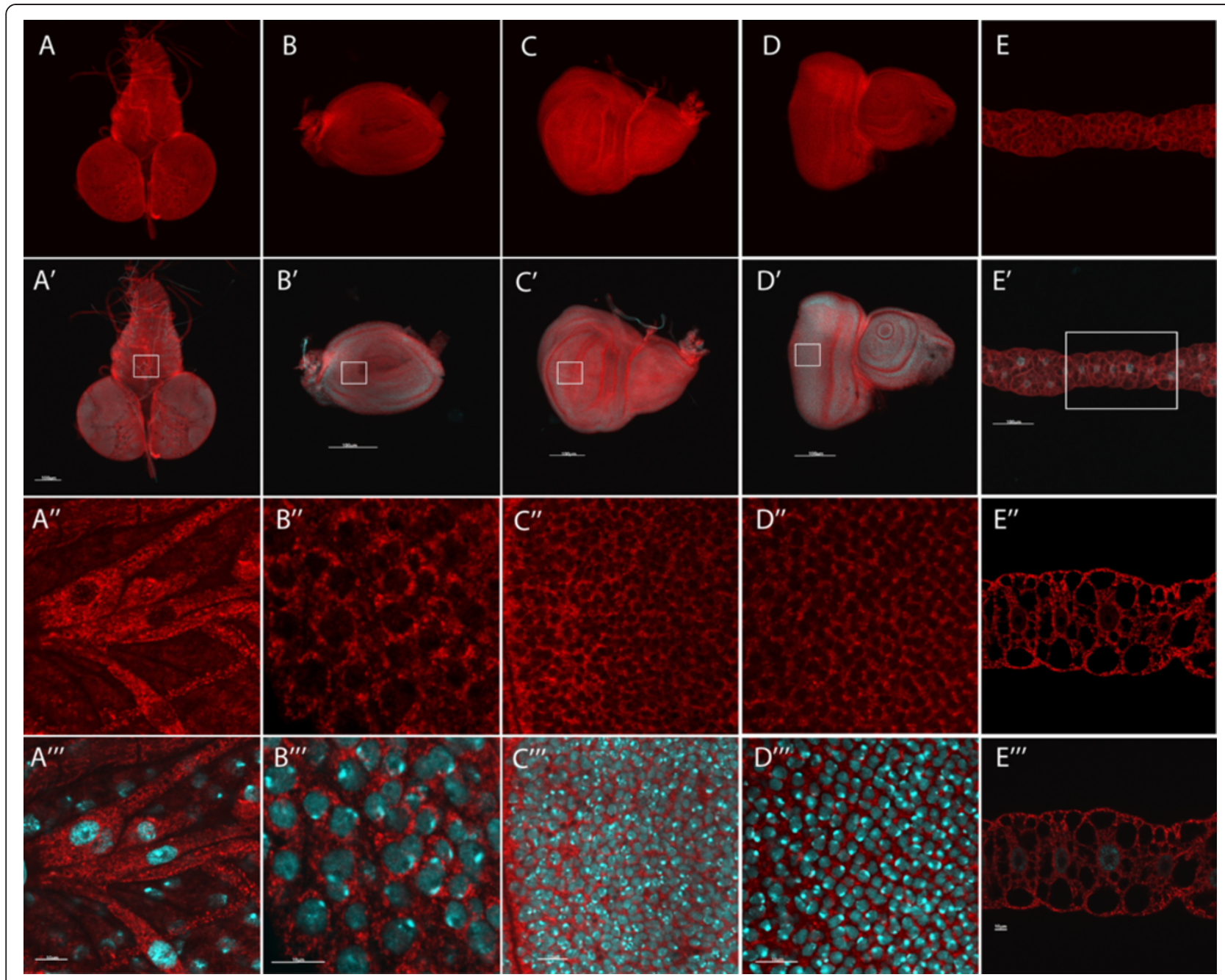

Figure 4 Ubiquitous expression dOSCP1 in various tissues. Brain lobe, fat body and several imaginal discs of third instar larvae

immunostained with anti-dOSCP1 antibody. (A) brain lobe, (B) leg disc, (C) wing disc, (D) eye disc, (E) fat body. Microscopic inspections were carried out under the same conditions for the immunostaining with the antibody preincubated with the purified His-dOSCP1 fusion protein (Additional file 1 : Figure S1). ( $\left(A^{\prime \prime}-E^{\prime \prime}\right)$ higher magnification images of the indicated regions of the upper panels. $\left(A^{\prime}-E^{\prime}\right)$ and $\left(A^{\prime \prime \prime}-E^{\prime \prime \prime}\right)$ Merged images of several imaginal discs with DAPI for nuclear staining (Blue) and anti-dOSCP1 antibody (Red). The bars indicate $100 \mu \mathrm{m}\left(\mathbf{A}^{\prime}-\mathbf{E}^{\prime}\right)$ or $10 \mu \mathrm{m}\left(\mathbf{A}^{\prime \prime \prime}-\mathbf{E}^{\prime \prime \prime}\right)$.

To further evaluate the signals with anti-dOSCP1 antibody, a flip-out experiment was employed to make a somatic clone expressing dOSCP1 dsRNA in the salivary glands. In RNAi clones marked with GFP, the level of dOSCP1 signals was specifically reduced (Figure 5I-M), thus confirming that the anti-dOSCP1 signals both in the cytoplasm and nucleus truly represent dOSCP1 protein.

\section{Localization of dOSCP1 protein on plasma membranes}

To confirm the localization of dOSCP1 in the cell membrane, we performed double-immunostaining assay with anti-dOSCP1 antibody and anti-Discs large (Dlg) antibody. Dlg has been reported as a component of septate junction structures in Drosophila epithelia cells [26]. Anti-Dlg antibody labels cell membranes and was therefore used here as a marker. Immunostaining showed signals with the
anti-dOSCP1 antibody to overlap those with the anti-Dlg antibody (Figure 6).

\section{Localization of dOSCP1 protein in subcellular organelles}

In immunostaining with salivary gland, we observed dOSCP1 signals in a mesh-like structure in the cytoplasm (Figure 5). As a first step to clarify the nature of this dOSCP1-positive structure, regarding the precise localization of the OSCP1 protein in the cytoplasm, double-immunostaining of the salivary gland with antidOSCP1 and specific antibodies for each organelle was performed.

To investigate the localization of dOSCP1 in the endoplasmic reticulum (ER), we used anti-dOSCP1 antibody and anti-KDEL antibody for double immunostaining of the third instar larval salivary gland. The anti-KDEL antibody 

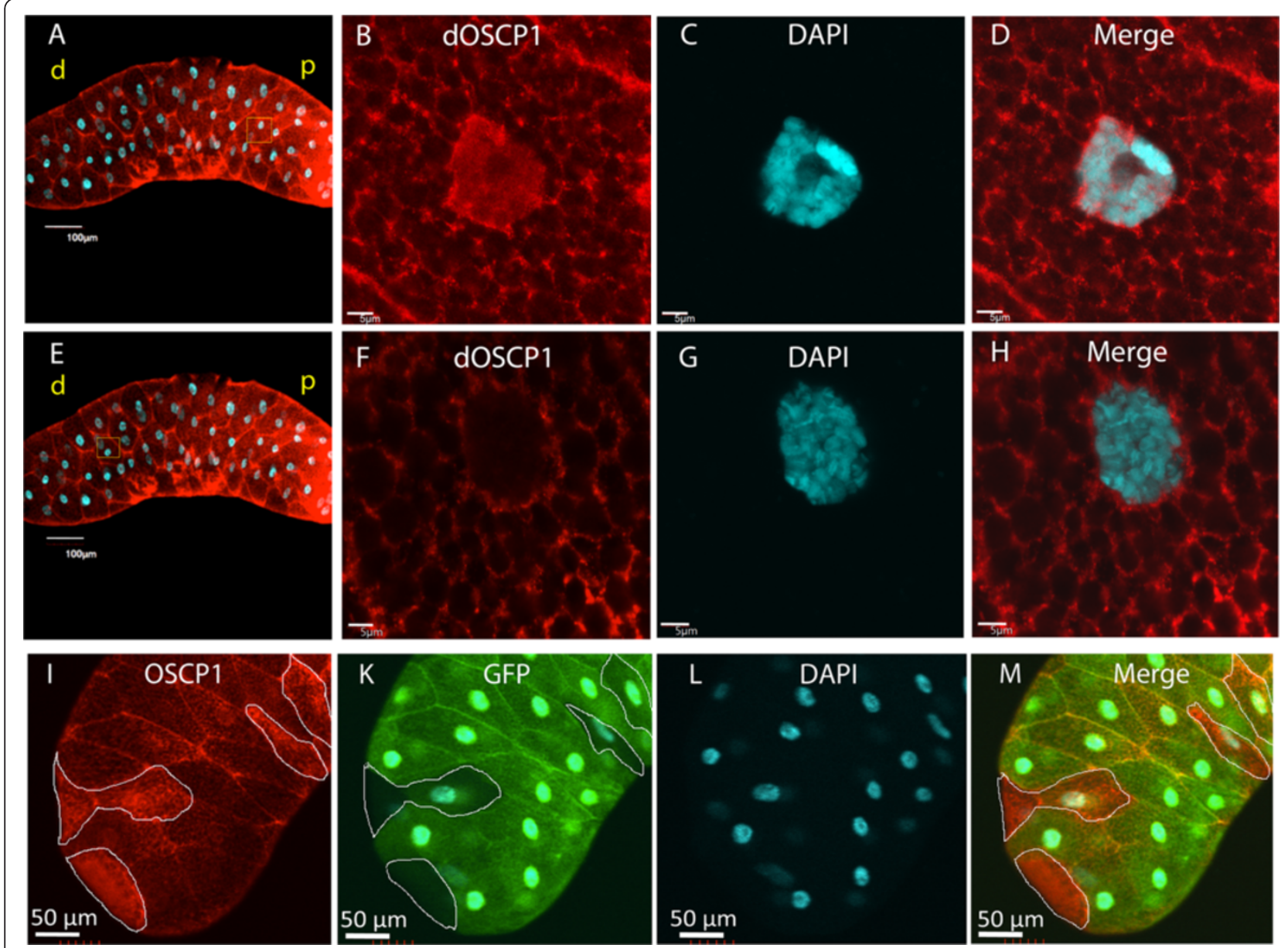

Figure $\mathbf{5}$ Localization of dOSCP1 in salivary gland cells. Salivary glands dissected from third instar larvae were stained with anti-dOSCP1 antibody and DAPI. (A-D) Image of proximal region. (A) Merged image of dOSCP1 signals and DAPI. (B-D) High magnification images of the proximal region. (B) dOSCP1 signals, (C) DAPI, (D) Merged image. A significant level of dOSCP1 signals was detected in the nuclei. (E-H) Image of distal region. (E) Merged image of dOSCP1 signal and DAPI. (F-H) High magnification images of the distal region. (F) dOSCP1 signals, (G) DAPI, (H) Merged image. No signals of dOSCP1 are evident in nuclei. (I-M) Image of flip-out expreriment. (I) OSCP1. (K) GFP. (L) DAPI. (M) Merged image. GFP-negative areas are enclosed. In the GFP-positive dOSCP1 RNAi clone area, levels of dOSCP1 signals are reduced. The bars indicate $100 \mu \mathrm{m}$ (A; E) or $50 \mu \mathrm{m}$ (B-D and I-M) or $5 \mu \mathrm{m}$ (F-H). p, proximal; d, distal.

has been used as the ER marker [27] which labels the sequence Lys-Asp-Glu-Leu (KDEL), or a closely related sequence, that is present at the carboxyl terminus of ER soluble and some membrane proteins [28-31]. Doubleimmunostaining showed co-localization of dOSCP1 and KDEL signals (Figure 7A-D). It is reported that in the salivary gland, KDEL signals are detectable not only in ER but also in cell and nuclear membranes [27]. This staining pattern with the anti-KDEL antibody appears to be intrinsic to this highly secreting tissue, since immunostaining of the cultured S2 cells with the same antibody showed signals in ER without any detectable signals in cell and nuclear membranes (Additional file 2: Figure S2). These results indicate that dOSCP1 localizes in ER.

To examine the localization of dOSCP1 in the Golgi apparatus, we employed double labeling with anti-dOSCP1 and anti-KDEL receptor antibodies. KDEL receptor is an integral membrane protein which mediates the retrieval of solute resident proteins from Golgi apparatus to the ER [28,32-34]. Some signals with anti-KDEL receptor in cell and nuclear membranes in addition to Golgi apparatus observed in this analysis are also reported with the salivary gland [27]. The results showed co-localization of dOSCP1 and KDEL receptor signals (Figure 8A-D).

To further evaluate the Golgi apparatus localization of dOSCP1, double immunostaining with anti-dOSCP1 and anti-GM130 antibodies was performed. The anti-GM130 antibody detects a peripheral membrane protein GM130 that binds to the Golgi complex [35]. The data showed overlapping signals (Figure 8E-H), further confirming the Golgi apparatus localization of dOSCP1. 

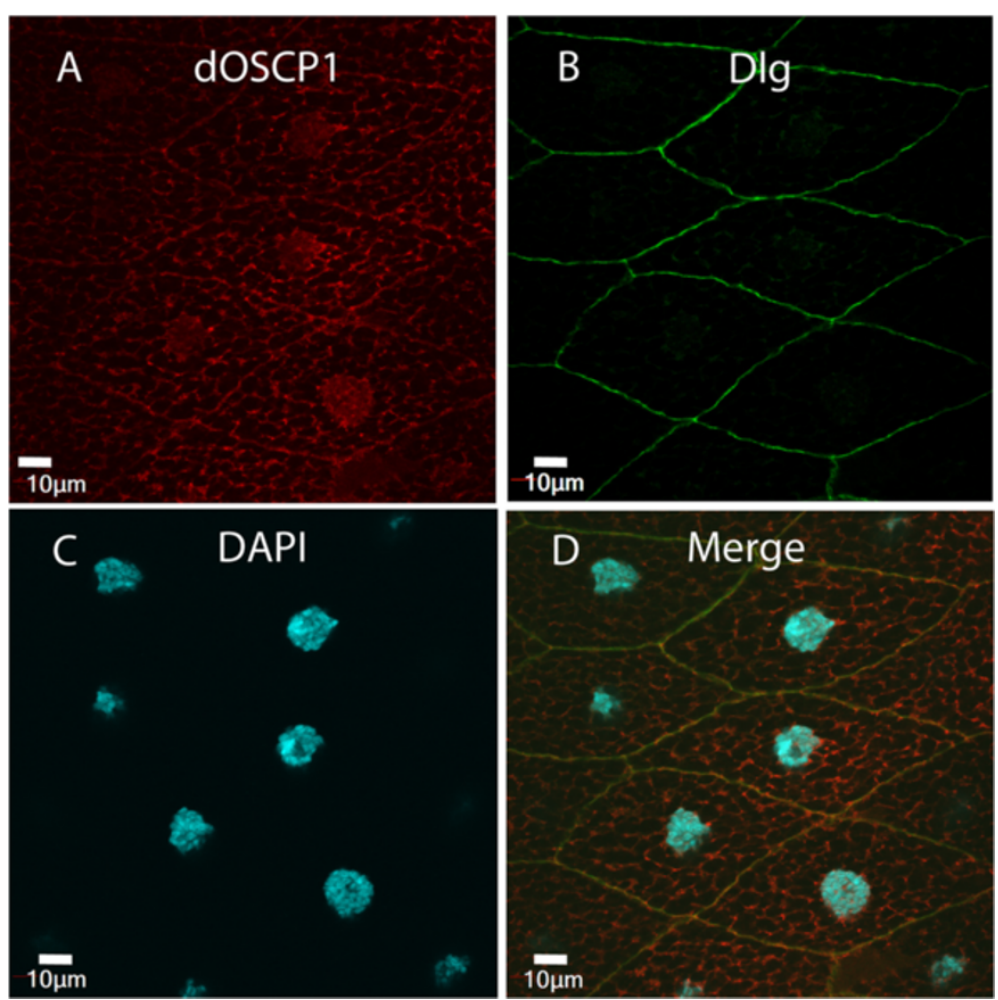

Figure 6 Plasma membrane localization of dOSCP1. Colocalization of dOSCP1 with Dlg. Salivary glands of third instar larvae were stained with anti-dOSCP1 (A), anti-Dlg (plasma membrane marker) (B) antibodies and DAPI (C). (D) Merged image. The bars indicate $10 \mu \mathrm{m}$.

In addition, localization of dOSCP1 in mitochondria was examined. To test this, the mitochondria protein HSP60 [36] was labeled with anti-HSP60 antibody. Double immunostaining with anti-dOSCP1 and antiHSP60 antibodies showed the co-localization in cytoplasmic dots (Figure 9A-D). Thus a mitochondrial localization of dOSCP1 was also demonstrated.

\section{Discussion}

OSCP1 has been reported to mediate the transport of various organic solutes such as organic anions and cations across the plasma membrane in a $\mathrm{pH}$-dependent and sodium-independent manner [8-10]. However, the underlying mechanisms of OSCP1 function have been unclear. Up to now, there has been no report on the structure of OSCP1 protein. Previous studies demonstrated that oligomerization of many transporter proteins plays an important role in movement of materials across cells [37-39]. Thus, oligomerization allows proteins to form large structures without increasing genome size and provides stability, while the reduced surface area of monomers in a complex can offer protection against denaturation $[18,40,41]$. Moreover, many proteins are known to self-assemble into oligomers to perform their biological functions [42]. In this study we found that dOSCP1 could form dimers and trimers in solution, which may be required for its transporter functions. Regarding membrane transporter proteins, dimerization and higher order oligomerization have actually been proposed as important factors that modulate their activity [43]. Therefore, further investigation of the dimerization of dOSCP1 would appear necessary to ascertain the underlying mechanisms of function.

In addition, several membrane transporters such as OATs are predicted to have a 12 membrane spanning domain [44], while the exceptions of OST $\alpha$ and OST $\beta$ predicted to have seven and one, respectively [20]. We used bioinformatics tools to gain insight into whether or not Drosophila OSCP1 carries a potential transmembrane domain(s). However, Kyte-Doolittle hydropathy analysis method indicated that Drosophila OSCP1 carries no potential transmembrane domain (http://gcat.davidson.edu/ DGPB/kd/kyte-doolittle.htm). The same prediction was obtained with the SMART program (http://smart.emblheidelberg.de/smart/set_mode.cgi?NORMAL $=1$ ) and the TMpred program (http://www.ch.embnet.org/software/ TMPRED_form.html). Furthermore, a previous study predicted that mouse OSCP1 does not carry any potential transmembrane domain [8]. These observations indicate that dOSCP1 may be not imbedded in the membrane but associated with some membrane bound proteins and consequently indirectly mediate and facilitate the transport of 

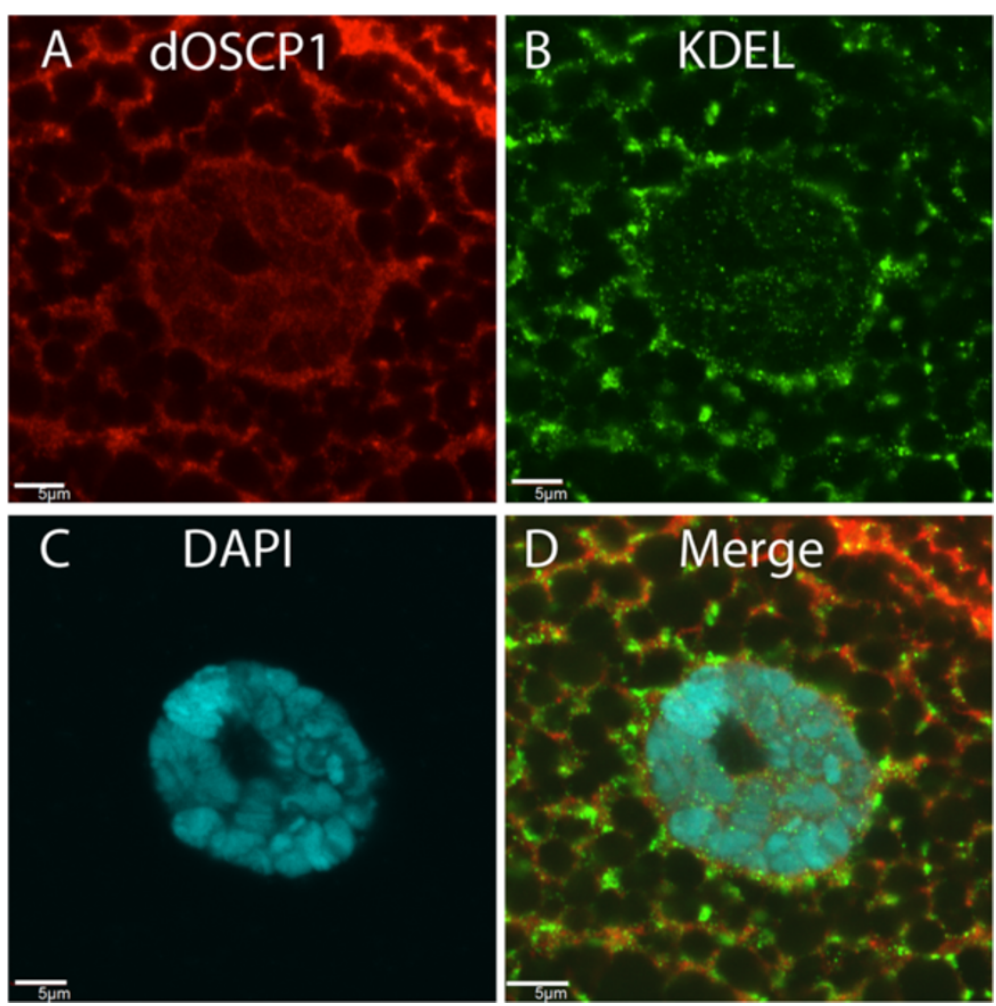

Figure 7 ER localization of dOSCP1. Salivary glands of third instar larvae coimmunostained with anti-dOSCP1 and anti-KDEL antibodies (A-D). DAPI was used to stain nuclei. The bars indicate $5 \mu \mathrm{m}$.

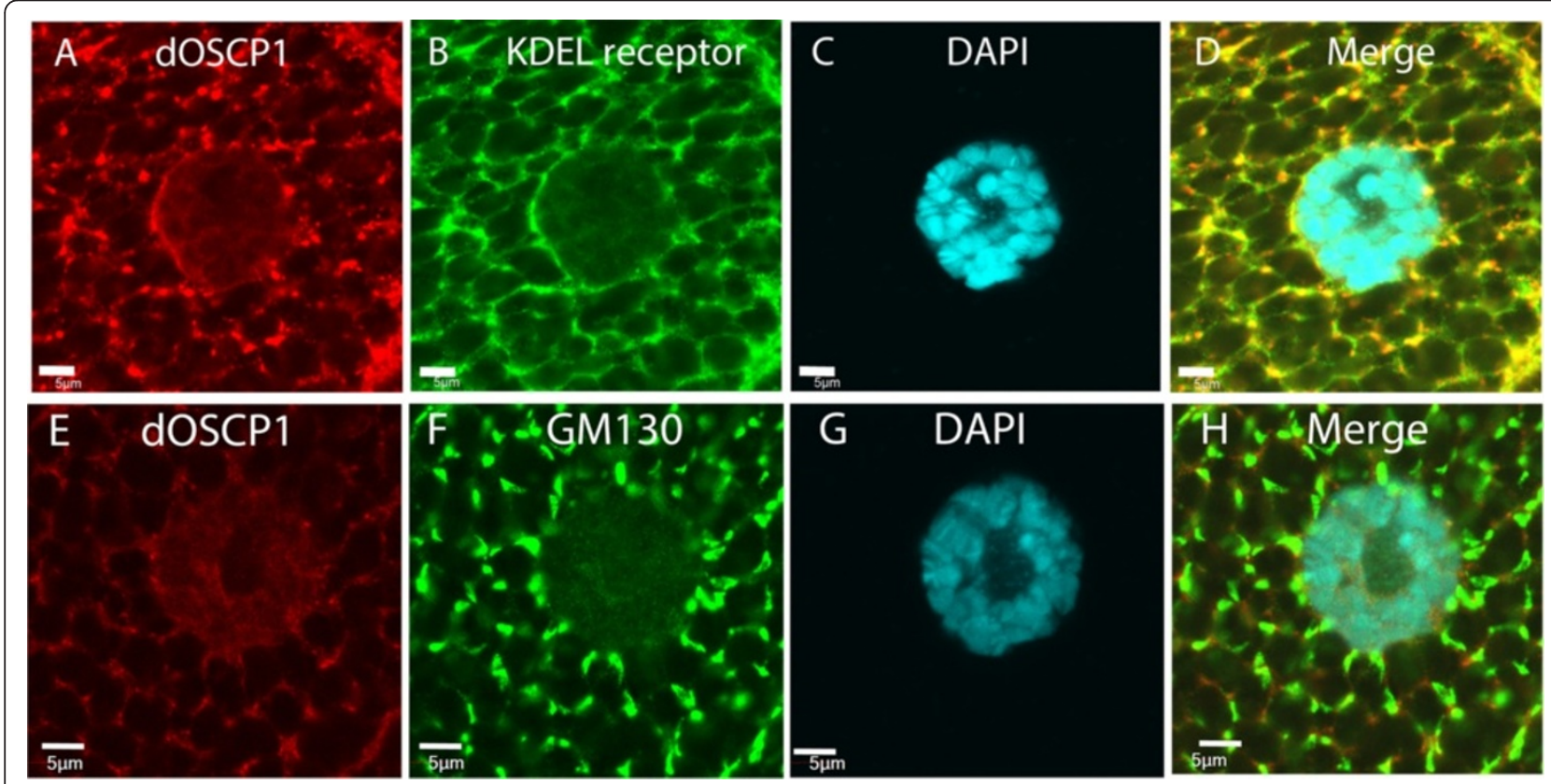

Figure 8 Golgi apparatus localization of dOSCP1. Salivary gland third instar larvae stained with anti-dOSCP1 (A), anti-KDEL receptor antibodies (upper panels) (A-D), or with anti-dOSCP1 and anti-GM130 antibodies (Golgi apparatus marker) (lower panels) (E-H). DAPI was used to stain nuclei. The bars indicate $5 \mu \mathrm{m}$. 


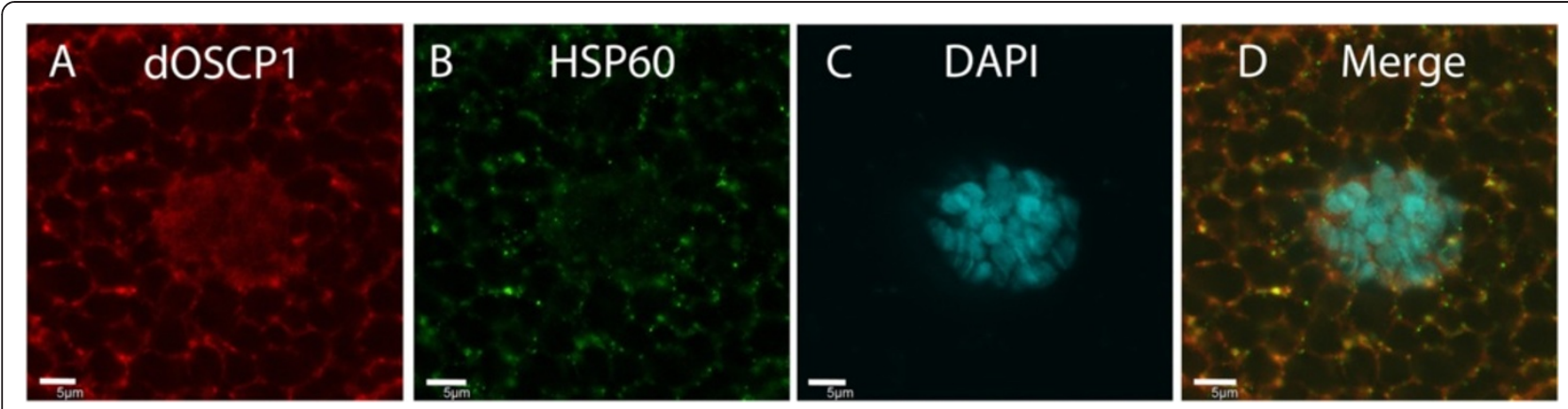

Figure 9 Mitochondria localization of dOSCP1. Salivary glands of third instar larvae stained with anti-dOSCP1 (A), anti-Heat shock protein 60 (HSP60) (mitochondria marker) (B) antibodies and DAPI (C). (D) Merged image. DAPI was used to stain nuclei. The bars indicate $5 \mu$ m.

organic solutes into the cells. It is well established that many proteins associated with the cell membrane are either directly or indirectly involved in membrane transport [45-47]. Multimeric complex formation was also reported for L-type amino acid transporter 1 with the 4EF2 heavy chain [48], and between OST $\alpha$ and OST $\beta$ [20]. Taken together these observations suggest that dOSCP1 may associate with other transporters to assist their functions. Future investigations should focus on whether OSCP1 acts as a regulator or a constituent of the functional transporter system in cells.

Various membrane transporters have been detected in different tissues including the blood-brain barrier, lung, heart, intestine and kidney [44]. The broad tissue distribution of human, mouse and rat OSCP1 has been well characterized, brain, lung, trachea, spinal chord and nasopharynx being included as shared sites $[9,11,13,14]$. Therefore, the present detection of dOSCP1 in various Drosophila larval tissues including brain lobes, eye discs, wing discs, leg discs, fat body and salivary glands suggests that the broad distribution pattern of OSCP1 is conserved among multiple species.

In addition to the dotted or mesh-like structures of dOSCP1 signals in the cytoplasm of the salivary glands, we detected some nuclear dOSCP1 signals in the proximal regions of the glands. In contrast, no nuclear signal was detectable in the distal region. It is known that most of cells in salivary glands of late stage of third instar larvae have completed polytenization in the distal region, but not in the proximal region [49]. Therefore dOSCP1 may play a role in nuclei of endoreplicating cells. Although dOSCP1 does not contain a canonical nuclear localization signal (NLS), the PSORT II tool based on the amino acid sequence predicts nuclear localization of dOSCP1 with 76.7\% reliability (http://psort.hgc.jp/form2. html). However, since we cannot exclude the possibility that the antibody may be more accessible to the proximal region, further analyses are necessary to confirm these observations.

\section{Conclusions}

In the present study, we could show that dOSCP1 localizes not only in the plasma membrane but also in the nucleus, ER, Golgi apparatus and mitochondria. It is therefore conceivable that this protein may interact with various partners or form multimeric complexes with other proteins to play multiple roles in cells. Whatever the case, the present data should help in furthering understanding of the roles of the dOSCP1 gene during Drosophila development.

\section{Methods}

\section{Sequence comparison of the OSCP1 gene}

The OSCP1 homologue sequence from the GeneBank database was analyzed in different species: (Homo sapiens) OSCP1 (NP_659484.4), (Pan troglodytes) OSCP1 (JAA 38622.1), (Macaca mulatta) OSCP1 (XP_002802362), (Mus musculus) OSCP1 (NP_766289.2), (Canis lupus) OSCP1 (XP_53256.3), (Bos Taurus) OSCP1 (NP_001039369.1), (Gallus gallus) OSCP1 (XP_001233001.1), (Rattus norvegicus) OSCP1 (NP_001025094.1), (Danio rerio) OSCP1 (XP_003201654.1), (Caenorhabditis elegans) R10F2.5 (NP_497640.1), (Drosophila melanogaster) CG13178 (AFF58577.1). Sequence alignment was performed using ClustalW2 software.

\section{Oligonucleotides}

For construction of pCold-dOSCP1, the following oligonucleotides were synthesized.

dOSCP1FXhol: 5'-CTCGGTACCCTCGAGATGCTCT ACGTGATCGATCAG-3'

dOSCP1REcoRI: 5'-GACAAGCTTGAATTCTCAAGG CATTTTGCTGTACAG-3'

\section{Plasmid construction}

To construct the plasmid pCold-dOSCP1, the full length cDNA of dOSCP1 was amplified by PCR with primers carrying XhoI and EcoRI sites and the amplified fragment was inserted into the plasmid pColdI (Takara, Japan) using an Infussion HD Kit (ClonTech, Japan) 


\section{Preparation of the recombinant dOSCP1-His fusion protein and production of anti-dOSCP1 antibody}

The amplified full length dOSCP1 cDNA carrying XhoI and EcoRI sites was cloned into the pColdI vector (Takara, Japan) to carry a $\mathrm{C}$ terminal His tag fusion sequence. After the nucleotide sequence was confirmed by sequencing, the plasmid was transformed into E. coli BL21. Expression of His-dOSCP1 fusion protein was carried out with a cold shock expression system (Takara, Japan). Cell lysates were prepared by sonication in PBS containing $1 \mathrm{mM}$ phenylmethylsulfonyl fluoride (PMSF) and 1\% SDS, then the supernatant and the pellets were separated by centrifugation at $12,000 \mathrm{~g}$ for $20 \mathrm{~min}$ at $4^{\circ} \mathrm{C}$. The supernatant was diluted with binding buffer $(500 \mathrm{mM} \mathrm{NaCl}, 50 \mathrm{mM}$ $\mathrm{NaH}_{2} \mathrm{PO} 4, \mathrm{pH}$ 8.0, $5 \mathrm{mM}$ Imidazol, $1 \mathrm{mM}$ PMSF) and purified with Ni-NTA agarose (QIAGEN, USA). After purification, the His-dOSCP1 fusion proteins were used to immunize a Guinea pig (SLC, Inc. Japan). Production of polyclonal antibodies was checked by Western blotting.

\section{Fly stocks}

Fly stocks were maintained at $25^{\circ} \mathrm{C}$ on standard food containing $0.7 \%$ agar, $5 \%$ glucose and $7 \%$ dry yeast. The transgenic fly line carrying glass minimal response element GMR-GAL4 on X chromosome was as described previously [50]. Fly lines carrying UAS- $d O S C P 1 I R_{466-609}$ were obtained from the Vienna Drosophila RNAi Center.

\section{Flip out experiments}

RNAi clones in Drosophila larval salivary gland were generated with a flip-out system [51]. Female flies with hs-flp; Act5C > FRT y FRT > Gal4, UAS-GFP were crossed with male flies carrying UAS-dOSCP1IR $R_{466-609}$. Clones were evaluated by the presence of green fluorescent protein (GFP) expressed under control of the Act5C promoter. Flip-out was induced by heat shock $(60 \mathrm{~min}$ at $37^{\circ} \mathrm{C}$ ) at $24-48$ hours after egg laying.

\section{Immunohistochemistry}

For immunohistochemistry, third instar larvae were dissected and fixed in 4\% paraformaldehyde/PBS for 15 min at $25^{\circ} \mathrm{C}$. After washing with $\mathrm{PBS} / 0.3 \%$ Triton $\mathrm{X}-100$ (PBS-T), the samples were blocked with PBS containing $0.15 \%$ Triton X-100 and $10 \%$ normal goat serum for $20 \mathrm{~min}$ at $25^{\circ} \mathrm{C}$ and incubated with primary antibodies for $16 \mathrm{~h}$ at $4^{\circ} \mathrm{C}$. The following antibodies were used: anti-dOSCP1 (1:100), mouse anti-Dlg (1:400) (Developmental Studies of Hybridoma Bank, DSHB), mouse anti-KDEL (1:800) (Enzo Life Sciences), mouse anti-KDEL receptor (1:300) (Abcam), rabbit anti-GM130 (1:200) (Abcam), mouse anti-HSP60 (1:200) (Enzo Life Sciences). For negative control, $10 \mu \mathrm{g}$ of Guinea pig IgG dOSCP1 antibody was incubated with $15 \mu \mathrm{g}$ of the purified His-dOSCP1 fusion protein for $16 \mathrm{~h}$ at $4^{\circ} \mathrm{C}$ and used as primary antibody (1:100). After washing with PBST, samples were incubated with secondary antibodies labeled with either Alexa 594 or Alexa 488 (1:400; Invitrogen, Tokyo, Japan) for 3 hours at $25^{\circ} \mathrm{C}$. Following further washing with $\mathrm{PBS} / 0.3 \%$ Triton $\mathrm{X}-100$ and with $\mathrm{PBS}$, the samples were stained with DAPI $(0.5 \mu \mathrm{g} / \mathrm{ml}) / \mathrm{PBS} /$ $0.1 \%$ Triton X-100. After washing with PBST and PBS, the samples were mounted and observed under a confocal laser scanning microscope (OLYMPUS Fluoview FV10i).

\section{Native-PAGE analysis}

Two $\mu \mathrm{g}$ and $4 \mu \mathrm{g}$ of His-dOSCP1 fusion protein were prepared in a non denaturing sample buffer $(62.5 \mathrm{mM}$ Tris-HCl pH 6.8, 25\% Glycerol, 1\% bromophenol blue) on ice [52] and denaturing sample buffer $(10 \% \beta$ mercaptoethanol, $4 \%$ sodium dodecyl sulfate, $20 \%$ glycerol, $0.25 \%$ bromophenol blue, $0.125 \mathrm{M}$ Tris- $\mathrm{HCl} \mathrm{pH}$ 6.8) in boiling water for $5 \mathrm{~min}$ [52]. Proteins were separated on polyacrylamide gels containing $10 \%$ acrylamide without SDS at a constant voltage of $100 \mathrm{~V}$ for 6 hours at $4^{\circ} \mathrm{C}$ [52]. The gels were then stained with Coomassie Brilliant Blue G-250 (CBB).

\section{SDS-PAGE and Western immunoblot analysis}

Eye imaginal discs of third instar larvae of wild type and transgenic flies carrying GMR-Gal4; UAS-dOSCP1IR; + were dissected in PBS and homogenized in an extraction buffer containing $50 \mathrm{mM}$ Tris- $\mathrm{HCl}$ (pH7.5), $5 \mathrm{mM}$ $\mathrm{MgCl} 2,150 \mathrm{mM} \mathrm{NaCl}, 10 \%$ glycerol, $0.1 \%$ Triton X-100, $0.1 \% \mathrm{NP}-40,10 \mu \mathrm{g} / \mathrm{ml}$ each of aprotinin, leupeptin and pepstatin $\mathrm{A}$ and $1 \mu \mathrm{g} / \mathrm{ml}$ each of antipain, chymostatin and phosphoramidon. Homogenates were centrifuged and total protein quantified by the Bradford method [53]. $30 \mu \mathrm{g}$ of proteins were boiled at $100^{\circ} \mathrm{C}$ for $5 \mathrm{~min}$, electrophoretically separated on SDS-polyacrylamide gels containing $10 \%$ acrylamide and then transferred to polyvinylidene difluoride membranes (Bio-Rad, USA). The membranes were blocked in TBS- $0.05 \%$ Tween 20 containing $5 \%$ skim milk for 1 hour at $25^{\circ} \mathrm{C}$, followed by incubation with mouse monoclonal anti-His antibody (DSHB) at 1:1500 or Guinea pig polyclonal anti-dOSCP1 antibody at 1:1500 dilution or mouse monoclonal anti- $\alpha$ tubulin antibody (DSHB) at 1:5000 for 16 hours at $4^{\circ} \mathrm{C}$. After washing 5 times with TBS, the membranes were incubated with HRP-conjugated rabbit anti-Guinea pig IgG $(\mathrm{H}+\mathrm{L})$ (Invitrogen, USA) at 1:10,000 dilution or stabilized peroxidase-conjugated goat anti-mouse $(\mathrm{H}+\mathrm{L}$ ) (Thermo Scientific, USA) at 1:5,000 dilution for 1 hour at $25^{\circ} \mathrm{C}$. Detection was performed with ECL Western blotting detection reagents (GE healthcare, USA). Images were captured by AE-9300H Ez-Capture MG system (ATTO corporation, Japan) and analyzed with Image Saver6 software (ATTO corporation, Japan). 


\section{Availability of supporting data}

The data sets supporting the results of this article are available in the LabArchves. The unique persistent identifier and hyperlink to data sets in https://mynotebook. labarchives.com/share/Masamitsu\%2520Yamaguchi/Mz IuNXwzOTQ2OS8yNS9UcmVlTm9kZS8xNjQ2ODMxOTAxfDgyLjU = (Additional file 1: Figure S1).

https://mynotebook.labarchives.com/share/Masamitsu\% 2520Yamaguchi/MzYuNHwzOTQ2OS8yOC9UcmVlT m9kZS8yODcxNjUyNTgyfDkyLjQ= (Additional file 2: Figure S2).

\section{Additional files}

Additional file 1: Figure S1. Identification of the absorption of anti-dOSCP1 antibody and His-dOSCP1 fusion proteins. Brain lobe, fat body and several imaginal discs of third instar larvae immunostained with anti-dOSCP1 antibody preincubated with the purified His-dOSCP1 fusion proteins. Microscopic inspections were carried out under the same conditions for the immunostaining with the antibody without preincubation (Figure 4). (A) brain lobe, (B) leg disc, (C) wing disc, (D) eye disc, (E) fat body, (F) salivary gland. $\left(A^{\prime \prime}-F^{\prime \prime}\right)$ higher magnification images of the indicated regions of the upper panels. $\left(A^{\prime}-F^{\prime}\right)$ and $\left(A^{\prime \prime \prime}-F^{\prime \prime \prime}\right)$ Merged images of several imaginal discs with DAPI (Blue) and anti-dOSCP1 antibody (Red). The bars indicate $100 \mu \mathrm{m}\left(\mathrm{A}^{\prime}-\mathrm{F}^{\prime}\right)$ or $10 \mu \mathrm{m}\left(\mathrm{A}^{\prime \prime \prime}-\mathrm{F}^{\prime \prime \prime}\right)$.

Additional file 2: Figure S2. Localization of KDEL, GM130 and KDEL receptor in cultured Drosophila S2 cells. Cells stained with anti-KDEL (A), anti-GM130 (B), anti-KDEL receptor (C) antibodies, (D) absence of the primary antibodies (Green) and DAPI (Blue). (A'-D') merged images. The bars indicate $10 \mu \mathrm{m}$.

\section{Abbreviations \\ OSCP1: Organic solute carrier partner 1; SLC: Solute carrier; ABC: ATP-binding cassette; OATPs: Organic anion transporting polypeptides; OCTs: Cation transporters; OATs: Organic anion transporters; PAH: P-aminohippurate; NOR1: Oxidored-nitro domain-containing protein 1; AML: Acute myeloid leukemia; NPCs: Nasopharyngeal carcinomas, signal; CBB: Coomassie brilliant blue G-250; NLS: Nuclear localization signal; UAS: Upstream activation sequence; Dlg: Discs large; ER: Endoplasmic reticulum; HSP60: Heat shock protein 60; SDS-PAGE: Sodium dodecyl sulfate-polyacrylamide gel electrophoresis; BPB: Bromophenol blue; dsRNA: Double strand RNA.}

\section{Competing interests}

The authors declare that they have no competing interests.

\section{Authors' contributions}

$\mathrm{NTH}$ conducted the experiments, analyzed the data. SM designed and performed the experiments to produce anti-dOSCP1 antibodies. TU performed the experiments for revision. NTH, HY and MY conceived and designed the study, edited and wrote the manuscripts. All authors read and approved the final manuscript.

\section{Acknowledgements}

We thank Dr. A. Plessis for supplying fly lines, and Dr. M. Moore for comments on the English in the manuscript. This study was partially supported by a scholarship and grants from the KIT, JST and and the JSPS Core-to-Core Program, B. Asia-Africa Science Platforms.

Received: 3 February 2014 Accepted: 13 June 2014 Published: 18 June 2014

\section{References}

1. Giacomini KM, Huang SM, Tweedie DJ, Benet LZ, Brouwer KLR, Chu XY, Dahlin A, Evers R, Fischer V, Hillgren KM, Hoffmaster KA, Ishikawa T, Keppler D, Kim RB, Lee CA, Niemi M, Polli JW, Sugiyama Y, Swaan PW, Ware JA,
Wright SH, Yee SW, Zamek-Gliszczynski MJ, Zhang L: Membrane transporters in drug development. Nat Rev Drug Discov 2010, 9(3):215-236.

2. Klaassen CD, Aleksunes LM: Xenobiotic, Bile Acid, and Cholesterol Transporters: Function and Regulation. Pharmacol Rev 2010, 62(1):1-96.

3. Hagenbuch B, Gui C: Xenobiotic transporters of the human organic anion transporting polypeptides (OATP) family. Xenobiotica 2008, 38(7-8):778-801.

4. Sekine $\mathrm{T}$, Cha $\mathrm{SH}$, Endou $\mathrm{H}$ : The multispecific organic anion transporter (OAT) family. Pflugers Arch 2000, 440(3):337-350.

5. Hediger MA, Romero MF, Peng JB, Rolfs A, Takanaga H, Bruford EA: The $A B C s$ of solute carriers: physiological, pathological and therapeutic implications of human membrane transport proteins - Introduction. Pflugers Arch 2004, 447(5):465-468.

6. Koepsell H, Lips K, Volk C: Polyspecific organic cation transporters: Structure, function, physiological roles, and biopharmaceutical implications. Pharm Res 2007, 24(7):1227-1251.

7. Eckhardt U, Schroeder A, Stieger B, Hochli M, Landmann L, Tynes R, Meier PJ, Hagenbuch B: Polyspecific substrate uptake by the hepatic organic anion transporter Oatp1 in stably transfected CHO cells. Am J Physiol 1999, 276(4):G1037-G1042.

8. Hiratsuka K, Yin SA, Ohtomo T, Fujita M, Ohtsuki K, Isaka H, Suga T, Kurosawa T, Yamada J: Intratesticular localization of the organic solute carrier protein, OSCP1, in spermatogenic cells in mice. Mol Reprod Dev 2008, 75(10):1495-1504.

9. Kobayashi Y, Shibusawa A, Saito H, Ohshiro N, Ohbayashi M, Kohyama N, Yamamoto $\mathrm{T}$ : Isolation and functional characterization of a novel organic solute carrier protein, hOSCP1. J Biol Chem 2005, 280(37):32332-32339.

10. Kobayashi Y, Tsuchiya A, Hayashi T, Kohyama N, Ohbayashi M, Yamamoto T: Isolation and characterization of polyspecific mouse organic solute carrier protein 1 (mOscp1). Drug Metab Dispos 2007, 35(7):1239-1245.

11. Izuno H, Kobayashi Y, Sanada Y, Nihei D, Suzuki M, Kohyama N, Ohbayashi $\mathrm{M}$, Yamamoto T: Rat organic solute carrier protein 1 (rOscp1) mediated the transport of organic solutes in Xenopus laevis oocytes: isolation and pharmacological characterization of rOscp1. Life Sci 2007, 81(15):1183-1192.

12. Nie XM, Zhang BC, Li XL, Xiang JJ, Xiao BY, Ma J, Zhou M, Zhu SG, Lu HB, Gui R, Shen SR, Li GY: Cloning, expression, and mutation analysis of NOR1, a novel human gene down-regulated in HNE1 nasopharyngeal carcinoma cell line. J Cancer Res Clin Oncol 2003, 129(7):410-414.

13. Xiang B, Yi M, Wang L, Liu W, Zhang WL, Ouyang J, Peng Y, Li WJ, Zhou M, Liu HY, Wu MH, Wang R, Li XL, Li GY: Preparation of polyclonal antibody specific for NOR1 and detection of its expression pattern in human tissues and nasopharyngeal carcinoma. Acta Biochim Biophys Sin (Shanghai) 2009, 41(9):754-762.

14. Ouyang J, Wu MH, Huang C, Cao L, Li GY: Overexpression of oxidored-nitro domain containing protein 1 inhibits human nasopharyngeal carcinoma and cervical cancer cell proliferation and induces apoptosis: Involvement of mitochondrial apoptotic pathways. Oncol Rep 2013, 29(1):79-86.

15. Li WJ, Li XL, Wang W, Li XY, Tan YX, Yi M, Yang JB, McCarthy JB, Xiong W, Wu MH, Ma J, Su B, Zhang ZP, Liao QJ, Xiang B, Li GY: NOR1 is an HSF1-and NRF1-regulated putative tumor suppressor inactivated by promoter hypermethylation in nasopharyngeal carcinoma. Carcinogenesis 2011, 32(9):1305-1314.

16. Xiang B, Wang W, Li WJ, Li XY, Li XL, Li GY: Differential expression of oxidored nitro domain containing protein 1 (NOR1), in mouse tissues and in normal and cancerous human tissues. Gene 2012, 493(1):18-26.

17. Kroeger H, Jelinek J, Estecio MRH, He R, Kondo K, Chung W, Zhang L, Shen LL, Kantarjian HM, Bueso-Ramos CE, Issa JPJ: Aberrant CpG island methylation in acute myeloid leukemia is accentuated at relapse. Blood 2008, 112(4):1366-1373.

18. Roth M, Obaidat A, Hagenbuch B: OATPs, OATs and OCTs: the organic anion and cation transporters of the SLCO and SLC22A gene superfamilies. Br J Pharmacol 2012, 165(5):1260-1287.

19. Burckhardt G, Wolff NA: Structure of renal organic anion and cation transporters. Am J Physiol Renal Physiol 2000, 278(6):F853-F866.

20. Seward DJ, Koh AS, Boyer JL, Ballatori N: Functional complementation between a novel mammalian polygenic transport complex and an evolutionarily ancient organic solute transporter, OST alpha-OST beta. J Biol Chem 2003, 278(30):27473-27482. 
21. Hiratsuka K, Momose A, Takagi N, Sasaki H, Yin SA, Fujita M, Ohtomo T, Tanonaka K, Toyoda H, Suzuki H, Kurosawa T, Yamada J: Neuronal expression, cytosolic localization, and developmental regulation of the organic solute carrier partner 1 in the mouse brain. Histochem Cell Biol 2011, 135(3):229-238.

22. Hashimoto R, Yamaguchi M: Dynamic changes in the subcellular localization of Drosophila beta-sarcoglycan during the cell cycle. Cell Struct Funct 2006, 31(2):173-180.

23. Shi WX, Chen ZL, Schottenfeld J, Stahl RC, Kunkel LM, Chan Y: Specific assembly pathway of sarcoglycans is dependent on beta- and delta-sarcoglycan. Muscle Nerve 2004, 29(3):409-419.

24. Signas C, Katze MG, Persson H, Philipson L: An adenovirus glycoprotein binds heavy-chains of class-I transplantation antigens from man and mouse. Nature 1982, 299(5879):175-178.

25. Bono MR, Strominger JL: Direct evidence of homology between human Dc-1 antigen and murine i-a molecules. Nature 1982, 299(5886):836-838.

26. Baumgartner S, Littleton JT, Broadie K, Bhat MA, Harbecke R, Lengyel JA, ChiquetEhrismann R, Prokop A, Bellen HJ: A Drosophila neurexin is required for septate junction and blood-nerve barrier formation and function. Cell 1996, 87(6):1059-1068.

27. Charroux B, Royet J: Mutations in the Drosophila ortholog of the vertebrate Golgi pH regulator (GPHR) protein disturb endoplasmic reticulum and Golgi organization and affect systemic growth. Biol Open 2014, 3(1):72-80.

28. Teasdale RD, Jackson MR: Signal-mediated sorting of membrane proteins between the endoplasmic reticulum and the Golgi apparatus. Annu Rev Cell Dev Biol 1996, 12:27-54.

29. Munro S, Pelham HRB: A C-Terminal signal prevents secretion of luminal er proteins. Cell 1987, 48(5):899-907.

30. Pelham HRB: Evidence that luminal ER proteins are sorted from secreted proteins in a post-ER compartment. Embo J 1988, 7(4):913-918.

31. Pelham HRB: The retention signal for soluble-proteins of the endoplasmic-reticulum. Trends Biochem Sci 1990, 15(12):483-486.

32. Lewis MJ, Pelham HRB: A human homolog of the yeast Hdel receptor. Nature 1990, 348(6297):162-163.

33. Lewis MJ, Pelham HR: Sequence of a second human KDEL receptor. J Mol Biol 1992, 226(4):913-916.

34. Tang BL, Wong SH, Qi XL, Low SH, Hong W: Molecular cloning, characterization, subcellular localization and dynamics of p23, the mammalian KDEL receptor. J Cell Bio/ 1993, 120(2):325-338.

35. Nakamura N, Rabouille C, Watson R, Nilsson T, Hui N, Slusarewicz P, Kreis TE, Warren G: Characterization of a cis-Golgi matrix protein, GM130. J Cell Biol 1995, 131(6 Pt 2):1715-1726.

36. Soltys BJ, Gupta RS: Immunoelectron microscopic localization of the 60kDa heat shock chaperonin protein (Hsp60) in mammalian cells. Exp Cell Res 1996, 222(1):16-27.

37. Aller SG, Eng ET, De Feo CJ, Unger VM: Eukaryotic CTR copper uptake transporters require two faces of the third transmembrane domain for helix packing, oligomerization, and function. J Biol Chem 2004, 279(51):53435-53441.

38. Richards MR, Listenberger LL, Kelly AA, Lewis SE, Ory DS, Schaffer JE: Oligomerization of the murine fatty acid transport protein 1. J Biol Chem 2003, 278(12):10477-10483.

39. Zottola RJ, Cloherty EK, Coderre PE, Hansen A, Hebert DN, Carruthers A: Glucose-transporter function is controlled by transporter oligomeric structure. A single, intramolecular disulfide promotes glut1 tetramerization. Biochemistry 1995, 34(30):9734-9747.

40. Hashimoto K, Panchenko AR: Mechanisms of protein oligomerization, the critical role of insertions and deletions in maintaining different oligomeric states. Proc Natl Acad Sci U S A 2010, 107(47):20352-20357.

41. Rizwan AN, Burckhardt G: Organic anion transporters of the SLC22 family: biopharmaceutical, physiological, and pathological roles. Pharm Res 2007, 24(3):450-470.

42. Poupon A, Janin J: Analysis and prediction of protein quaternary structure. Methods Mol Biol 2010, 609:349-364.

43. Veenhoff LM, Heuberger EH, Poolman B: Quaternary structure and function of transport proteins. Trends Biochem Sci 2002, 27(5):242-249.

44. Hagenbuch B, Meier PJ: The superfamily of organic anion transporting polypeptides. Biochim Biophys Acta 2003, 1609(1):1-18.

45. Dantzig AH, Hoskins J, Tabas LB, Bright S, Shepard RL, Jenkins IL, Duckworth DC, Sportsman JR, Mackensen D, Rosteck PR, Skatrud PL: Association of Intestinal Peptide-Transport with a Protein Related to the Cadherin Superfamily. Science 1994, 264(5157):430-433.
46. Cools J, Mentens N, Marynen P: A new family of small, palmitoylated, membrane-associated proteins, characterized by the presence of a cysteine-rich hydrophobic motif. FEBS Lett 2001, 492(3):204-209.

47. Chamberlain LH, Burgoyne RD: The cysteine-string domain of the secretory vesicle cysteine-string protein is required for membrane targeting. Biochem J 1998, 335:205-209.

48. Kanai $Y$, Segawa H, Miyamoto K, Uchino H, Takeda E, Endou H: Expression cloning and characterization of a transporter for large neutral amino acids activated by the heavy chain of 4 F2 antigen (CD98). J Biol Chem 1998, 273(37):23629-23632.

49. Yamaguchi M, Hirose F, Nishimoto Y, Naruge T, Ikeda M, Hachiya T, Tamai K, Kuroda K, Matsukage A: Expression patterns of DNA replication enzymes and the regulatory factor DREF during Drosophila development analyzed with specific antibodies. Biol Cell 1995, 85(2-3):147-155.

50. Hirose F, Ohshima N, Shiraki M, Inoue YH, Taguchi O, Nishi Y, Matsukage A, Yamaguchi M: Ectopic expression of DREF induces DNA synthesis, apoptosis, and unusual morphogenesis in the Drosophila eye imaginal disc: Possible interaction with polycomb and trithorax group proteins. Mol Cell Biol 2001, 21(21):7231-7242.

51. Sun JT, Tower J: FLP recombinase-mediated induction of $\mathrm{Cu} / \mathrm{Zn}$-superoxide dismutase transgene expression can extend the life span of adult Drosophila melanogaster flies. Mol Cell Biol 1999, 19(1):216-228.

52. Srivastava S, Gupta PS: SDS and Native page protein profile for identification and characterization of elite sugarcane genotypes. Sugar Tech 2002, 4(3-4):143-147.

53. Bradford MM: A rapid and sensitive method for the quantitation of microgram quantities of protein utilizing the principle of protein-dye binding. Anal Biochem 1976, 72:248-254.

doi:10.1186/1471-2091-15-11

Cite this article as: Huu et al:: Structural characterization and subcellular localization of Drosophila organic solute carrier partner 1. BMC

Biochemistry 2014 15:11.

\section{Submit your next manuscript to BioMed Central and take full advantage of:}

- Convenient online submission

- Thorough peer review

- No space constraints or color figure charges

- Immediate publication on acceptance

- Inclusion in PubMed, CAS, Scopus and Google Scholar

- Research which is freely available for redistribution 